\title{
Crystal structure of disodium dimanganate(II), $\mathrm{Na}_{2} \mathrm{Mn}_{2} \mathrm{O}_{3}$
}

\author{
Steffen Pfeiffer and Martin Jansen* \\ Max-Planck-Institut für Festkörperforschung, Heisenbergstraße 1, 70569 Stuttgart, Germany
}

Received January 22, 2009, accepted and available on-line February 14, 2009; CSD no. 409981

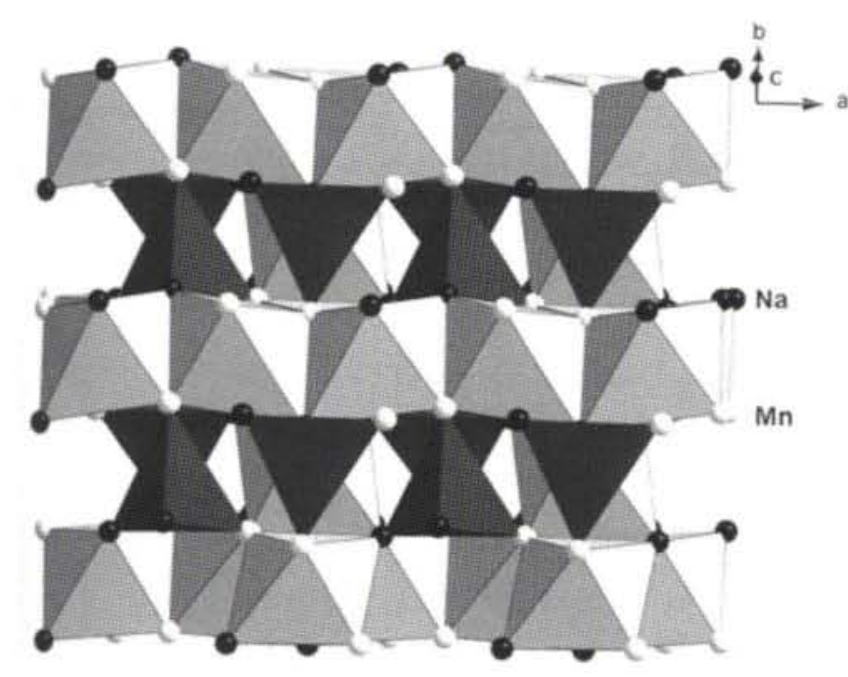

Abstract

$\mathrm{Mn}_{2} \mathrm{Na}_{2} \mathrm{O}_{3}$, tetragonal, $P 4_{3} 2{ }_{1} 2$ (no. 96), $a=6.4205(9) \AA$, $c=9.477(2) \AA, V=390.6 \AA^{3}, Z=4, R_{g r}(F)=0.025$, $w R_{\text {ref }}\left(F^{2}\right)=0.058, T=293 \mathrm{~K}$.

\section{Source of material}

The title compound was obtained via the azide/nitrate route [1]. Starting materials for the preparation of $\mathrm{Na}_{2} \mathrm{Mn}_{2} \mathrm{O}_{3}$ were $\mathrm{NaN}_{3}$ (Sigma-Aldrich, $99.5 \%$ ), $\mathrm{NaNO}_{2}$ (Riedel-de Haën, purest) and $\mathrm{Mn}_{3} \mathrm{O}_{4}$ (Alfa Aesar, $97+\%$ ). The precursors were mixed in the ratios required according to the equation: $11 \mathrm{NaN}_{3}+\mathrm{NaNO}_{2}+$ $4 \mathrm{Mn}_{3} \mathrm{O}_{4}=6 \mathrm{Na}_{2} \mathrm{Mn}_{2} \mathrm{O}_{3}+17 \mathrm{~N}_{2}$. This mixture was ground down thoroughly in an agate mortar, pressed to a pellet, dried under vacuum at $403 \mathrm{~K}$ for $12 \mathrm{~h}$ and placed under argon in a tightly closed steel container provided with a silver inlay [2]. In a flow of dried Ar the following temperature profile was applied: $298 \mathrm{~K}$ to $533 \mathrm{~K}$ $(100 \mathrm{~K} / \mathrm{h}), 533 \mathrm{~K}$ to $653 \mathrm{~K}(5 \mathrm{~K} / \mathrm{h}), 653$ to $773 \mathrm{~K}(20 \mathrm{~K} / \mathrm{h})$, and subsequent annealing for $30 \mathrm{~h}$ at $773 \mathrm{~K}$. The obtained red powder is sensitive to air and moisture. Transparent red single crystals have

been grown by annealing a mixture of $\mathrm{NaN}_{3}$ (Sigma-Aldrich, $99.5 \%$ ), $\mathrm{NaNO}_{3}$ (Sigma-Aldrich, $99 \%$ ) and $\mathrm{Mn}_{2} \mathrm{O}_{3}$ (Chempur, $99.9 \%$ ) in the ratio $4: 1: 1$ at $773 \mathrm{~K}$ for $1000 \mathrm{~h}$ in silver crucibles, which were sealed in glass ampoules under dried $\mathrm{Ar}$.

\section{Discussion}

$\mathrm{Na}_{2} \mathrm{Mn}_{2} \mathrm{O}_{3}$ is isostructural to $\mathrm{Na}_{2} \mathrm{Zn}_{2} \mathrm{O}_{3}$ [3]. The main feature of the crystal structure are corner- and edge-sharing $\mathrm{MnO}_{4}$ tetrahedra, which built up a three-dimensional framework. The $\mathbf{M n}-\mathrm{O}$ bond distances are in the range from 1.995 to $2.136 \AA$, the $\mathrm{O}-\mathrm{Na}-$ $O$ angles lie between $92.8^{\circ}$ and $123.2^{\circ}$. The bond lenghts are thus in the expected range, and very similar to those found in $\mathrm{Na}_{2} \mathrm{MnO}_{2}$ [4] and $\mathrm{Na}_{10} \mathrm{Mn}_{4} \mathrm{O}_{9}$ [5]. Since there is no simple ordering principle underlying the anion packing an approach suggested by O'Keefe and Hyde [6] is used to describe the crystal structure, which is based on the packing of cations with the voids beeing filled by anions. In $\mathrm{Na}_{2} \mathrm{Mn}_{2} \mathrm{O}_{3}$ the cations form an approximate cubic close packed arrangement. There are two alternating double layers consisting of cations, where in the first one 3/4 of the octahedral voids are filled with oxygen, in the second layer $1 / 4$ of the tetrahedral and $1 / 4$ of the octahedral voids are filled with oxygen atoms. The resulting coordination-polyhedra are all edgeand corner-sharing. The structure of $\mathrm{Na}_{2} \mathrm{Mn}_{2} \mathrm{O}_{3}$ may therefore be regarded an anti-type of the spinel structure.

Table 1. Data collection and handling.

Crystal:

Wavelength:

$\mu$ :

Diffractometer, scan mode:

$2 \theta_{\max }$ :

$N(h k l)_{\text {measured, }} N(h k l)_{\text {unique: }}$

Criterion for $I_{\text {obs, }} N(h k l)_{g t}$ :

$N(\text { param })_{\text {refined: }}$

Programs:

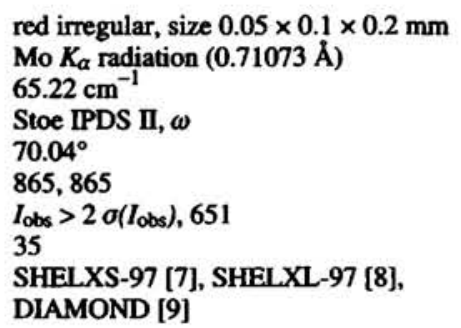

Table 2. Atomic coordinates and displacement parameters (in $\AA^{2}$ ).

\begin{tabular}{lllllllllll}
\hline Atom & Site & $x$ & $y$ & $z$ & $U_{11}$ & $U_{22}$ & $U_{33}$ & $U_{12}$ & $U_{13}$ & $U_{23}$ \\
\hline $\mathrm{Mn}(1)$ & $8 b$ & $0.7535(1)$ & $0.54232(7)$ & $0.11387(5)$ & $0.0088(2)$ & $0.0088(2)$ & $0.0085(2)$ & $-0.0006(2)$ & $0.0005(2)$ & $0.0009(2)$ \\
$\mathrm{Na}(1)$ & $8 b$ & $0.4755(2)$ & $0.2601(3)$ & $0.8618(1)$ & $0.0113(5)$ & $0.0173(5)$ & $0.0129(5)$ & $-0.0019(7)$ & $0.0011(5)$ & $-0.0002(7)$ \\
$\mathrm{O}(1)$ & $8 b$ & $0.0000(3)$ & $0.2572(7)$ & $0.6461(2)$ & $0.0100(8)$ & $0.0097(9)$ & $0.0088(8)$ & $-0.0014(6)$ & $0.0014(5)$ & $-0.002(2)$ \\
$\mathrm{O}(2)$ & $4 a$ & $0.1844(4)$ & $x$ & 0 & $0.0151(9)$ & $U_{11}$ & $0.012(1)$ & $0.001(1)$ & $-0.0031(7)$ & $U_{13}$ \\
\hline
\end{tabular}

\footnotetext{
* Correspondence author (e-mail: M.Jansen @ fkf.mpg.de)
} 


\section{References}

1. Trinschek, D.; Jansen, M.: A new and simple route to alkali metal oxometalates. Angew. Chem.; Int. Ed. 33 (1998) 133-135.

2. Sofin, M.; Peters, E.-M.; Jansen, M.: Ein neuartiges Polyoxocobaltat(II)Anion in $\mathrm{Rb}_{2} \mathrm{Co}_{2} \mathrm{O}_{3}$. Z. Anorg. Allg. Chem. 628 (2002) 2697-2700.

3. Trinschek, D.; Jansen, $\mathrm{M}$.: Eine neue Modifikation von $\mathrm{Na}_{2} \mathrm{Zn}_{2} \mathrm{O}_{3}$. $\mathrm{Z}$. Naturforsch. 51B (1996) 917-921.

4. Pfeiffer, S.; Jansen, M.: Synthesis, Crystal Structure and Properties of $\mathrm{Na}_{2} \mathrm{MnO}_{2}$. Z. Anorg. Allg. Chem. 635 (2009) 211-215.

5. Amann, P.; Sobotka, B. M.; Fastje, O.; Möller, A.: Synthesis and crystal structure of $\mathrm{Na}_{10}\left[\mathrm{Mn}_{3} \mathrm{O}_{6}\right]\left[\mathrm{MnO}_{3}\right](\mathrm{M}=\mathrm{Fe}, \mathrm{Mn})$ with a remark on the magnetic properties. Z. Anorg. Allg. Chem. 633 (2007) 2579-2586.
6. O'Keefe, M.; Hyde, B. G.: An Alternative Approach to Non-Molecular Crystal Structures - with Emphasis on the Arrangements of Cations. Structure and Bonding. Springer Verlag Berlin Heidelberg 1985.

7. Sheldrick, G. M.: SHELXS-97. Program for Solving Crystal Structures. University of Göttingen, Germany 1997.

8. Sheldrick, G. M.: SHELXL-97. Program for the Refinement of Crystal Structures. University of Göttingen, Germany 1997.

9. Brandenburg. K.: DLAMOND. Visual Crystal Structure Information System. Version 2. le. Crystal Impact GbR, Bonn, Germany 2001. 